Abbvie, Amgen, Lilly, Target BioScience, Pfizer. In addition, he holds a patent issued "mir-29 for the treatment of systemic sclerosis" (US8247389, EP2331143)., Grant/research support from: Has received grants/research support in the are of potential treatments for systemic sclerosis from Actelion, Bayer, Boehringer Ingelheim, Kymera Therapeutics, Mitsubishi Tanabe Pharma DOI: 10.1136/annrheumdis-2021-eular.3028

\section{POS0333 ALTERED MACROPHAGE POLARIZATION PHENOTYPES IN SYSTEMIC SCLEROSIS}

A. Hukara ${ }^{1}$, M. Rudnik ${ }^{1}$, C. B. Rufer ${ }^{1}$, O. Distler ${ }^{1}$, P. Blyszczuk ${ }^{1}$, G. Kania ${ }^{1}$ ${ }^{1}$ University Hospital Zurich, University of Zurich, Department of Rheumatology, Center of Experimental Rheumatology, Zurich, Switzerland

Background: Fos-like 2 (Fosl-2) is a transcription factor of the AP-1 family and has a broad range in inducing cellular changes affecting fibrosis and inflammatory responses. Pathological effects of Fosl-2 have been associated with systemic sclerosis (SSc). In addition, increased expression of Fosl-2 has been detected in human SSc monocyte-derived macrophages [1]. Monocytes and macrophages play a central role in activating and propagating acute inflammation followed by pathological fibrosis and organ dysfunction. The classification of the macrophage polarization phenotype can be assigned based on the stimulus, for example into classically-activated M(LPS), and alternatively-activated M(IL-4) macrophages [2]. However, the role of the Fosl-2 transcription factor in macrophage polarization remains elusive. Objectives: To investigate the role of Fosl-2 in macrophage polarization in SSc using Fosl-2 overexpressing transgenic (Fosl-2 tg) mice and human blood-derived macrophages from SSc patients.

Methods: Thiogylcolate-elicited peritoneal macrophages were isolated from wildtype (wt) and Fosl-2 tg mice. Human peripheral CD14 ${ }^{+}$blood-derived monocytes were isolated and differentiated to macrophages (hMDM) from healthy controls and SSc patients. Murine and human macrophages were polarized with LPS $(10 \mathrm{ng} / \mathrm{ml})$, LPS + recombinant mouse IFN- $\gamma(10 \mathrm{ng} / \mathrm{ml})$, recombinant mouse, resp. human IL-4 $(10 \mathrm{ng} / \mathrm{ml})$ or remained untreated. Macrophage surface marker expression was assessed by flow cytometry using a mouse (F4/80, CD11b, CD86, CD80, CD38, MHCII, CD206, PD-L1, PD-L2, CD36) or human (CD38, CD40, CD86, PD-L2, PD-L1, CD163, CD206) designed polarization panel. Phagocytic activity was detected with pHrodo Red E.coli particles by flow cytometry. Gene expression and secretion of pro- and anti-inflammatory markers were measured by RT-qPCR, standard ELISAs and Griess Assay for nitric oxide production.

Results: After LPS stimulation, mRNA levels of IL-1 $\beta(p<0.01, n=11-12)$, TNF- $\alpha$ $(p=0.05, n=11-12)$ and IFN- $\gamma(p<0.05, n=7)$ were reduced, whereas expression of IL-10 $(p<0.05, n=11-12)$ was enhanced in Fosl-2 tg peritoneal macrophages in comparison to wt cells. Secretion of TNF- $\alpha(p<0.01, n=9-11)$ and nitric oxide $(p<0.01, n=9)$ was impaired in Fosl-2 tg peritoneal macrophages compared to wt cells after LPS stimulation. Peritoneal macrophages were analyzed directly after isolation for macrophage polarization cell surface marker expression. Fosl-2 tg peritoneal macrophages showed an increase in the F4/80 ${ }^{+} \mathrm{CD} 11 \mathrm{~b}^{+} \mathrm{PD}-\mathrm{L}_{2}{ }^{+} \mathrm{CD} 36^{+}$ cell population ( $p<0.01, n=3-6$ ) compared to peritoneal macrophages from wt mice. The expression of cell surface markers of non-polarized and IL-4 stimulated SSc hMDM $(n=17)$ showed an increased percentage of $C D 40^{+} C D 86^{+} C D 206^{+} P D-$ $\mathrm{L}^{+} \mathrm{CD}_{163^{+}}$cells $(\mathrm{p}<0.05)$ compared to healthy control hMDM $(\mathrm{n}=7)$. Phagocytic activity was enhanced in SSc hMDM $(n=7)$ compared to healthy untreated $(p<0.05)$, LPS $(p=0.05)$ and IL-4 $(p<0.05)$ hMDM $(n=5)$.

Conclusion: Our animal data indicates a role of Fosl-2 in regulating macrophage polarization with a shift from a classically-activated to an alternatively-activated phenotype. Similarly, SSc hMDM resemble a functional M(IL-4) alternative macrophage phenotype. Thus, maintaining a balanced proportion of classically- and alternatively-activated macrophage phenotypes may be an effective tool to control macrophage function in SSc.

\section{REFERENCES:}

[1] Moreno-Moral, A., et al., Changes in macrophage transcriptome associate with systemic sclerosis and mediate GSDMA contribution to disease risk. Ann Rheum Dis, 2018. 77(4): p. 596-601.

[2] Kania, G., M. Rudnik, and O. Distler, Involvement of the myeloid cell compartment in fibrogenesis and systemic sclerosis. Nat Rev Rheumatol, 2019. 15(5): p. 288-302.

Disclosure of Interests: Amela Hukara: None declared, Michal Rudnik: None declared, Chantal Brigitta Rufer: None declared, Oliver Distler Speakers bureau: Actelion, Bayer, Boehringer Ingelheim, Medscape, Novartis, Roche, Menarini, Mepha, MSD, iQone, Pfizer, Consultant of: Abbvie, Actelion, Acceleron Pharma, Amgen, AnaMar, Arxx Therapeutics, Bayer, Baecon Discovery, Blade Therapeutics, Boehringer, CSL Behring, ChemomAb, Corpuspharma, Curzion Pharmaceuticals, Ergonex, Galapagos NV, GSK, Glenmark Pharmaceuticals, Inventiva, Italfarmaco, iQvia, Kymera, Medac, Medscape, Mitsubishi Tanabe Pharma, MSD, Roche, Sanofi, UCB, Lilly, Target BioScience, Pfizer, Grant/research support from: Actelion, Bayer, Boehringer Ingelheim, Kymera Therapeutics, Mitsubishi Tanabe, Przemyslaw Blyszczuk: None declared, Gabriela Kania: None declared DOI: 10.1136/annrheumdis-2021-eular.3124

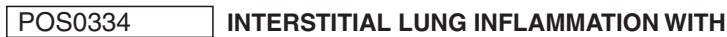 ALVEOLAR HEMORRHAGE IN AUTOIMMUNE MRL/ MP-LPR/LPR MICE}

S. Sato ${ }^{1} .{ }^{1}$ Saitama Children's Medical Center, Division of Infectious Diseases and Immunology and Allergy, Saitama, Japan

Background: Anti-melanoma differentiation-associated gene 5 (MDA5) antibody is associated with interstitial lung disease (ILD) in patients with juvenile dermatomyositis (JDM). Although the mechanisms leading to pulmonary involvements remain uncertain, both inflammatory cytokines and autoimmune response between MDA5 and anti-MDA5 antibody could been inferred. The present study examined the roles of MDA5 in an inducible form of lung involvement that develops in autoimmune mice treated with the pristane.

Objectives: MRL/Mp-lpr/lpr mice and wild type controls $(+/+)$ at 5 weeks of age. They received $0.5 \mathrm{ml}$ of pristane or an equal volume of PBS IP at the age 7 week (day 1). And $1.2 \mu \mathrm{g}$ of recombinant human MDA5 protein (rMDA5) was instilled IP or PBS at day2 and Day9. The mice were sacrificed on 8 weeks after the intraperitoneal injection. Lung tissue was harvested for histological assessment Methods: MRL/Mp-Ipr/Ipr mice and wild type controls $(+/+)$ at 5 weeks of age. They received $0.5 \mathrm{ml}$ of pristane or an equal volume of PBS IP at the age 7 week (day 1). And $1.2 \mu \mathrm{g}$ of recombinant human MDA5 protein (rMDA5) was instilled IP or PBS at day2 and Day9. The mice were sacrificed on 8 weeks after the intraperitoneal injection. Lung tissue was harvested for histological assessment. Results: Lung involvements did not develop in PBS-treated MRL/lpr mice and WT mice. And Lung involvements did not develop in rMDA5 protein-treated WT mice. H\&E staining of lung tissue from MRL/Ipr mice and WT mouse with pristane that showed induced bland alveolar hemorrhage. H\&E staining of lung from WT mouse compared with lung from a MRL/lpr mouse treated with pristane + rMDA5 protein showing mild thickening of the alveolar septa despite the alveolar hemorrhage. And perivascular lymphocytes infiltrate in a MRL/lpr mouse rather than a WT mouse treated with pristane + rMDA5 protein. CD163 staining of alveolar macrophages were present in the alveolar spaces was more intense in mouse treated with pristane + rMDA5 protein than in mouuse treated with only pristane. The Lymphocyte infiltrations around alveolar macrophages was more prominent in MRL/Ipr mouse treated with pristane + rMDA5 protein than other mouse.

Conclusion: These results suggest that lung involvements such as the alveolar hemorrhage, are caused by pristeine and rMDA5 prtotein in the pathogenesis of interstitial pneumonia. MRL/Ipr mouse treated with pristane + rMDA5 protein showed more alveolar macrophages that had lymphocyte infiltrations. After the alveolar hemorrhage by pritane, the antigen exposure of MDA5 might induce continuously inflammatory response to lymphocytes and macrophages in the alveolar lesions.

\section{REFERENCES:}

[1] Sunderrajan VE, McKenzie NW, Lieske RT, et al. Pulmonary inflammation in autoimmune MRL/Mp-lpr/lpr mice. Histopathology and bronchoalveolar lavage evaluation. Am J Pathol. 1986;124: 353-362.

[2] Tolga Barker T, Lee YP, Scumpia KK, et al. Pathogenic role of B-cells in the development of diffuse alveolar hemorrhage induced by pristane. Lab Invest 2011; 91: 1540-1550.

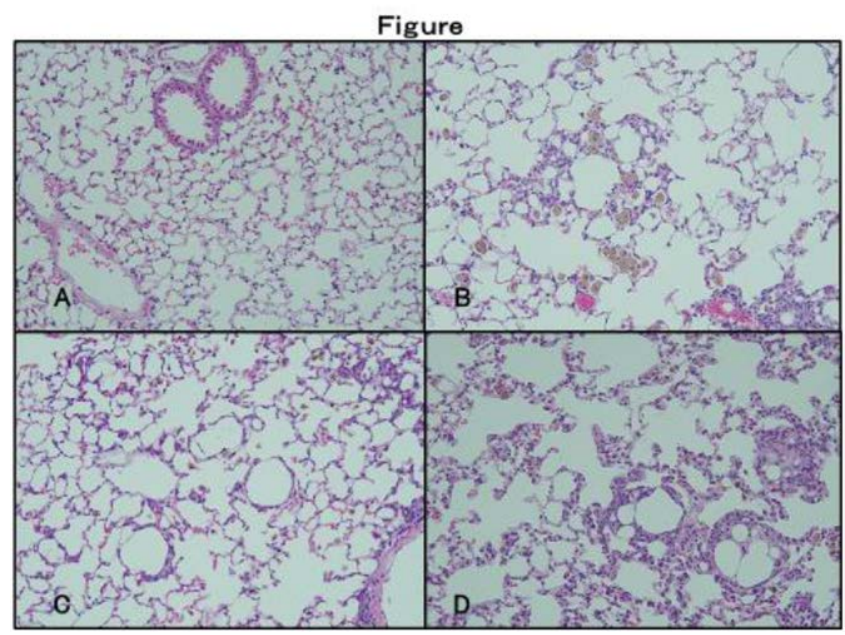

Figure 1. Lung disease (A-D).Light microscopy. Lung tissue from mice 8 weeks after treatment were stained with H\&E. (A) Pristeine -treated WT mice with almost no alveolar lesions. (B) Pristane + rMDA5 protein -treated WT mice with alveolar hemorrhage and slight lymphocyte infiltrations. (C) Pristeine -treated MRL/lpr mouse with almost no alveolar lesions and sligh lymphocyte infiltrations. (D) Pristeine -treated MRL/lpr mouse with alveolar hemorrhage and lymphocyte infiltrations, thickening of the alveolar septa.

Disclosure of Interests: None declared DOI: 10.1136/annrheumdis-2021-eular.3411 